\title{
A economia política do Fundo de Amparo ao Trabalhador (FAT): uma análise de seu desempenho recente (2005-2018)
}

\author{
The political economy of the Workers' Assitance Fund: \\ an analysis of its recent performance (2005-2018)
}

RESUMO: Este estudo analisou os fatores políticos e econômicos que condicionaram a evolução recente do sistema público de emprego no Brasil, tendo como foco os mecanismos operacionais do Fundo de Amparo ao Trabalhador (FAT). Com base em informações contábeis dos exercícios anuais, constatou-se que tal arranjo de financiamento vem demonstrando sinais de fragilidade, com diminuição da capacidade de custear o conjunto de suas despesas correntes. Contudo, os desequilíbrios são explicados em grande parte por decisões de política econômica que provocaram vazamentos expressivos em suas receitas nos últimos anos, sobretudo via desvinculações orçamentárias e desonerações tributárias.

PALAVRAS-CHAVE: Sistema público de emprego; Fundo de Amparo ao Trabalhador; políticas sociais; mudança institucional; mercado de trabalho.

ABSTRACT: This study analyzed the political and economic factors that conditioned the recent evolution of the public employment system in Brazil, focusing on the operational mechanisms of the Workers' Assistance Fund (FAT). Based on the accounting information of the annual periods, it was found that such financing arrangement has shown signs of fragility, with a reduction in the capacity to cover all of its current expenses. However, the imbalances are largely explained by economic policy decisions that have caused significant leaks in recent years, especially budget disengagement and tax relief.

KEYWORDS: Public employment system; Workers' Assistance Fund; social policy; institutional change; job market.

JEL Classification: E22; E62; E65; H53; I38; J38; J68.

\footnotetext{
*Instituto de Pesquisas Econômicas Aplicadas - IPEA, Rio de Janeiro/RJ, Brasil. E-mail: sandroecbr@ yahoo.com.br. Orcid: https://orcid.org/0000-0002-8836-0128. Submetido: 1/Abril/2019; Aprovado: 15/ Setembro/2020.
} 


\section{INTRODUÇÃO}

A temática da proteção contra o desemprego involuntário, envolvendo tanto assistência financeira quanto oferta de serviços públicos de ativação do mercado de trabalho, compreende um domínio de intervenção estatal comum a todos os países que adotaram sistemas próprios de políticas de bem-estar social. Os desenhos de programas com esses objetivos foram influenciados, em grande medida, pelo conceito de Sistema Público de Emprego, construído e difundido pela Organização Internacional do Trabalho (OIT) ao longo do século XX. No Brasil, após algumas tentativas fracassadas ou negligenciadas, foi somente com a Constituição Federal de 1988 (CF/1988) que se estruturou uma estratégia para a operacionalização de um conjunto de programas governamentais que atendem aos requisitos propostos pela OIT, tendo como eixo estruturante o Programa de Seguro-Desemprego (Silva, 2020a).

Para suprir a necessidade de financiamento dessa estratégia, foi constituído em 1990 o Fundo de Amparo ao Trabalhador (FAT), com fontes próprias de receitas para a execução dos programas incluídos no que passou a ser chamado posteriormente de Sistema Público de Emprego, Trabalho e Renda (SPETR). No entanto, a gestão de um fundo contábil de tal vulto - um dos maiores da América Latina - não está isenta de uma série de interesses que dificultam ainda mais sua coordenação e, por conseguinte, sua sustentabilidade. $\mathrm{O}$ estabelecimento e a gestão de suas normas operacionais nem sempre ocorrem de maneira harmoniosa e procedimental, dado o próprio conflito de interesses que define a relação dos principais grupos envolvidos: empresários, trabalhadores e governo.

Nessa perspectiva, este artigo analisou a trajetória de institucionalização e financiamento do SPETR brasileiro, buscando ressaltar os fatores políticos e econômicos mais relevantes que condicionaram seu funcionamento e sua atual condição operacional. Para isso, o foco recaiu sobre o arranjo normativo arquitetado em torno do FAT, dada sua importância para garantir a execução dos programas a ele conectados. O rastreamento analítico permitiu admitir que, embora a engenharia institucional do FAT tenha mantido sua estrutura básica original, um conjunto de mudanças de natureza fiscalista foi inserido ao longo dos anos afetando gravemente sua dinâmica de funcionamento e capacidade operativa, sobretudo no tocante à disponibilidade financeira para a implementação e expansão dos programas.

As principais fontes de dados utilizadas foram os relatórios e demonstrativos de execução financeira do FAT, além de outras estatísticas orçamentárias e cadastrais do antigo Ministério do Trabalho (MTb). ${ }^{1}$ Algumas entrevistas com gestores

\footnotetext{
${ }^{1}$ Como as análises têm como limite temporal o ano de 2018, manteve-se o nome do Ministério do Trabalho e sua sigla MTb vigente à época. Em janeiro de 2019, com o fim desse ministério, as funções referentes às políticas de emprego e gestão do próprio FAT passaram a integrar o Ministério da Economia.
} 
e técnicos administrativos responsáveis pela gestão do FAT também foram realizadas de forma complementar.

O texto está dividido da seguinte forma. Na segunda seção são relatados brevemente os principais fatos históricos que forneceram as bases para a institucionalização do SPETR, culminando com a CF/1988. Na terceira seção há uma caracterização geral do arranjo de financiamento do SPETR, com base na Lei $n^{\circ} 7.998 / 1990$, que o regulamentou e dispôs sobre a criação do FAT. Na quarta seção a discussão está centrada na dinâmica financeira propriamente dita do FAT, com seus fluxos de entrada, de obrigações e evolução patrimonial, problematizando decisões de política fiscal que geraram distorções em sua disponibilidade financeira para o período 2005-2018. Por fim, são tecidas algumas considerações conclusivas.

\section{POLÍTICAS PÚBLICAS DE TRABALHO NO BRASIL}

As políticas públicas voltadas à proteção e geração de trabalho e renda no Brasil foram construídas ao longo do século XX sob distintos contextos políticos e socioeconômicos (Silva, 2020b). Um dos marcos principais dessa construção institucional é a criação do próprio Ministério do Trabalho, Indústria e Comércio, em 1930, no governo de Getulio Vargas. Durante os anos seguintes, surgiram várias normativas que foram proporcionando a inserção de um conjunto maior de trabalhadores, ligados a diferentes setores econômicos, a um sistema público de proteção social, apesar de suas fragilidades (Carvalho, 2002; Pochmann, 2008; Silva, 2020a).

Diversos fatores foram relevantes para essa construção histórica. Uma delas refere-se ao processo de avanço internacional das instituições de bem-estar social na grande maioria dos países industrializados durante o século XX, que consolidou e disseminou o paradigma do welfare state (Esping-Andersen, 1990; Kerstenetsky, 2012). No entanto, a relação de transferência institucional não ocorreu de forma "automática", e sim com base em grandes disputas em torno de diferentes projetos políticos e concepções de desenvolvimento.

Nesse contexto, a OIT despontou como ator externo importante para a emulação no plano político interno de padrões internacionais de políticas e de regulação trabalhista. Desde sua criação, em 1919, logo após o fim da Primeira Guerra Mundial, a OIT vem pautando a criação de quadros propositivos a serem disseminados em seus países-membros para a construção de políticas nacionais que respeitem em suas bases os direitos sociais do conjunto dos trabalhadores. Nesse sentido, foram aprovadas resoluções que contribuíram para o comprometimento entre os países signatários em incorporar diretrizes normativas em cada um dos distintos contextos jurídicos nacionais. Duas delas, publicadas já no contexto pós-Segunda Guerra Mundial, merecem destaque por sua relevância na construção e disseminação do modelo de sistema público de emprego. A primeira refere-se à Convenção ${ }^{\circ}$ 88/1948, que avançou na organização de diretrizes para serviços de emprego, de caráter público e gratuito, em um mundo em reconstrução. A segunda é a Convenção n 102/1952, que estabeleceu "normas mínimas para a seguridade social”, com 
critérios para o que chama de "prestações de desemprego", a serem destinadas na forma de um pagamento periódico aos indivíduos que se encontrassem em situação de desemprego involuntário.

As duas convenções citadas foram ratificadas pelo Brasil, o que gerou internamente um compromisso político de adotar programas com essas características para a formação de uma rede de apoio e assistência aos trabalhadores. No entanto, pouca coisa havia sido criada no país que convergisse com as diretrizes aprovadas pela OIT nos anos subsequentes.

Entre as experiências ocorridas dignas de nota, uma delas foi o Programa Intensivo de Preparação de Mão de Obra para a Indústria (PIPMOI), lançado em 1963, ainda sob o governo de João Goulart. Embora tenha sido proposto como um programa de existência transitória, ele foi mantido pelos governos militares, com algumas mudanças em seu conteúdo (Barradas, 1986). O PIPMOI inseriu o tema da formação profissional na agenda governamental de forma estruturada em um programa próprio, primeiramente no Ministério da Educação e depois no Ministério do Trabalho, em parceria com órgãos privados encarregados da prestação dos serviços. ${ }^{2}$ Porém, suas ações foram perdendo força até que o programa fosse totalmente extinto no contexto de crise econômica no início dos anos 1980.

Em 1965, no governo militar de Castelo Branco, foi sancionada a Lei $\mathrm{n}^{\circ}$ 4.923, que estabeleceu o primeiro esboço para a construção de um sistema público de emprego no Brasil. Por ela foi criado o Cadastro Geral de Empregados e Desempregados (Caged), para o registro das admissões e dispensas efetuadas por todas as empresas brasileiras, a ser usado como base para um "plano de assistência aos trabalhadores" em situação de desemprego por dispensa injustificada ou por fechamento total ou parcial da empresa. Para seu financiamento, a lei autorizava a constituição do Fundo de Assistência ao Desempregado (FAD), composto por tributos sobre a folha de salários e uma parcela da contribuição sindical. No entanto, a Lei $n^{\circ} 4.923 / 1965$ surtiu pouco efeito prático para a constituição de um programa de seguro-desemprego, pois não houve elaboração de plano algum, tampouco nenhuma regulamentação posterior. $\mathrm{O}$ próprio $\mathrm{FAD}$, criado para garantir os recursos necessários, não chegou a ter alguma efetividade digna de reconhecimento.

Ainda no período militar, o presidente Ernesto Geisel lançou nova estratégia de atendimento às já referidas convenções da OIT, com a criação do Sistema Nacional de Emprego (SINE), por meio do Decreto $n^{\circ} 76.403 / 1975$. Sua missão consistia em prover uma série de serviços de intermediação entre vagas disponíveis e trabalhadores em busca de emprego para potencializar o funcionamento do mercado de trabalho no país. A gestão ficaria a cargo do Ministério do Trabalho, com postos de atendimento nos estados mediante parcerias junto aos governos estaduais.

\footnotetext{
${ }^{2}$ Em 1972, por meio do Decreto $n^{\circ} 70.882$, o governo ampliou as ações do programa para todos os setores da economia, não mais se restringindo à indústria, alterando-se o nome para Programa Intensivo de Preparação de Mão de Obra (PIPMO).
} 
Contudo, uma série de fatores restringiu a capacidade dessa nova estrutura em promover dinâmicas efetivas de proteção social e dinamização do mercado de trabalho, em especial a falta de uma fonte de financiamento estável.

Somente em 1986 o Brasil passou a contar de fato com um programa de seguro-desemprego. José Sarney havia assumido no ano anterior como o primeiro presidente civil, ainda que de forma indireta, após vinte anos de sucessivos presidentes militares. Nesse contexto, com vistas a enfrentar o cenário de crise econômica que o país enfrentava desde o início da década, o governo federal lançou o Plano Cruzado, por meio do Decreto-Lei n ${ }^{\circ}$ 2.284/1986. O texto afirmava em seu preâmbulo dispor sobre o "sistema monetário brasileiro", o "seguro-desemprego" e as "medidas de combate à inflação".

Sem entrar na discussão sobre os resultados do novo plano econômico, o fato é que o seguro-desemprego entrou finalmente na agenda governamental, com a finalidade de "prover assistência financeira temporária ao trabalhador desempregado em virtude de dispensa sem justa causa, ou por paralisação, total ou parcial, das atividades do empregador" (art. 25). Entretanto, a combinação entre critérios restritivos de elegibilidade, em relação a programas similares na Europa, e instabilidade quanto às fontes de financiamento, fez com que a cobertura do novo programa fosse bastante modesta em seus primeiros anos de vigência. De julho de 1986 até o final de 1987, somente 885 mil trabalhadores foram atendidos, e sua cobertura em relação ao total de demitidos sem justa causa não chegou a $5 \%$ em 1986, passando a 10,9\% no ano seguinte (Azeredo, 1998).

Tais questões limitantes foram objeto de discussão no âmbito da Assembleia Nacional Constituinte (ANC), instalada no dia $1^{\circ}$ de fevereiro de 1987. Após uma longa jornada em comissões, subcomissões e plenários por quase dois anos, foi promulgada a Constituição Federal brasileira, em 5 de outubro de 1988 (CF/1988), cujo artigo 239 dispôs sobre a criação de um novo fundo para o financiamento do seguro-desemprego e demais políticas de mercado de trabalho. Os recursos seriam provenientes do Programa de Integração Social (PIS) e do Programa de Formação do Patrimônio do Servidor Público (Pasep), que são contribuições sociais de natureza tributária calculados sobre o faturamento operacional bruto de empresas privadas e públicas. Mas nem todo o recurso oriundo do PIS-Pasep seria destinado diretamente às políticas de mercado de trabalho, pois $40 \%$ de sua arrecadação anual líquida seria repassada ao Banco Nacional de Desenvolvimento Econômico e Social (BNDES) para o financiamento de projetos de investimento, com critérios de remuneração que lhes preservem o valor. Esse montante acumulado anualmente viria a constituir o patrimônio do fundo (Silva, 2019b). ${ }^{3}$

Destaca-se também que o referido artigo 239 da CF/1988 garantiu o pagamento do Abono Salarial, um tipo de assistência financeira direcionada a trabalhadores empregados inscritos no PIS-Pasep há pelo menos cinco anos, com rendimento

\footnotetext{
${ }^{3}$ Havia ainda a previsão de uma "contribuição adicional" a ser cobrada de empresas com índices de rotatividade da força de trabalho superiores à média de seu setor $\left(\mathbb{4} 4^{\circ}\right.$, art. 239). No entanto, esse parágrafo nunca foi regulamentado.
} 
mensal de até 2 salários mínimos (SM). A esses trabalhadores ficou assegurado o pagamento de $1 \mathrm{SM}$ anual.

Dessa forma, ficaram definidas as diretrizes gerais para a estruturação de sistema público de emprego no Brasil. As seções seguintes abordam esse processo.

\section{O FAT E SUA ESTRUTURA OPERACIONAL E ORÇAMENTÁRIA}

A regulamentação do artigo 239 ocorreu com a Lei n ${ }^{\circ} 7.998$, de 11 de janeiro de 1990, pela qual foi criado o Fundo de Amparo ao Trabalhador (FAT) como integrante do orçamento da seguridade social. Por ela foi estabelecido também a criação do Conselho Deliberativo do Fundo de Amparo ao Trabalhador (Codefat), composto de forma tripartite, com a representação paritária de organizações ligadas aos trabalhadores, aos empregadores e órgãos da estrutura estatal. O Codefat ficou incumbido de tomar as decisões estratégicas sobre os programas componentes do SPETR, acompanhar suas operações e responder pelas obrigações e pelos recursos que lhes são atribuídos (Silva, 2019a).

Logo no ano seguinte à regulamentação do FAT, outra lei (Lei n ${ }^{\circ}$ 8.352/1991) estipulou novas regras para aplicações de seus recursos, onde ficou expressa a necessidade de se manter parte das disponibilidades financeiras para a formação de uma Reserva Mínima de Liquidez (RML), como um mecanismo financeiro para "garantir, em tempo hábil, os recursos necessários ao pagamento das despesas referentes ao Programa Seguro-Desemprego e ao Abono" $\left(\right.$ art. $\left.1^{\circ}\right)$. Os seus recursos devem ser aplicados em títulos do Tesouro Nacional (fundos extramercado), e na medida em que houvesse disponibilidade excedente, estes poderiam ser aplicados na forma de “Depósitos Especiais”, em instituições bancárias públicas nacionais (Silva, 2019b). Trata-se da concessão de linhas especiais de crédito a micro e pequenas empresas com potencial de geração de novos postos de trabalho e renda. A remuneração referente a essas transações seria incluída como receita financeira do FAT.

Com isso, o FAT passou a ser o pilar fundamental para o funcionamento do SPETR, pois seu arranjo normativo proporcionou as capacidades estatais necessárias para a implementação de um sistema complexo de programas voltados à proteção e à promoção do emprego, englobando ações de assistência financeira, intermediação laboral e qualificação profissional. Além do PIS-Pasep, mantido como principal item de arrecadação primária do fundo, sua estrutura de financiamento é complementada por fontes menores como a cota-parte da contribuição sindical, bem como por fontes secundárias (que tiveram importância crescente ao longo dos anos), referentes às remunerações de seus ativos financeiros compostos pelos repasses constitucionais ao BNDES para o financiamento de projetos de infraestrutura e desenvolvimento econômico, a remuneração sobre a RML e os Depósitos Especiais em instituições bancárias públicas. ${ }^{4}$

\footnotetext{
${ }^{4}$ Para maiores detalhes sobre os mecanismos de financiamento do FAT e sua relação com o BNDES, ver Silva $(2018,2019 b)$.
} 
Isso posto, o patrimônio financeiro inicial do FAT foi formado pela diferença entre o que foi arrecadado via PIS-Pasep e o total de desembolsos para pagamentos do seguro-desemprego e do abono salarial entre outubro de 1988 e sua implementação em 1990. A esse valor, acrescia-se ainda o montante de juros e correções monetárias referentes à parcela da arrecadação anual repassada ao BNDES durante o mesmo período.

O FAT apresentou um considerável crescimento patrimonial em seus primeiros anos, em virtude de uma relativa "folga" financeira. As despesas totais de custeio, incluídos o seguro-desemprego, o abono salarial e os demais serviços de apoio ao trabalhador, mesmo somadas às transferências direcionadas ao BNDES, mantiveram-se inferiores à arrecadação líquida do PIS-Pasep e demais fontes de receita (Azeredo, 1998).

Em 1994, no contexto da complexa estratégia que envolveu o novo plano de estabilização monetária da economia brasileira - o Plano Real -, o governo federal implementou novo artifício de política fiscal que impactou diretamente o fluxo de receitas do FAT. Trata-se do Fundo Social de Emergência (FSE), que previa a desvinculação de $20 \%$ de recursos arrecadados de contribuições sociais para a livre disponibilização por parte do governo federal. Apesar do FSE apresentar vigência programada até 31 de dezembro de 1995, a norma foi renovada desde então pelos diferentes presidentes posteriores, primeiramente com o nome de Fundo de Estabilização Fiscal (FEF), e depois, com a EC n ${ }^{\circ} 27 / 2000$, passou-se a utilizar o nome de Desvinculação de Recursos da União (DRU).

Dada essa sequência de decisões e alterações normativas, a estrutura orçamentária do FAT pode ser sintetizada com base no Quadro 1, na página seguinte.

O artifício da desvinculação de receitas iniciado em 1994 gerou, desde então, uma transferência corrente das fontes de financiamento da seguridade social (incluindo o PIS-Pasep) para o orçamento da União, em uma clara distorção dos propósitos que motivaram sua criação. Com isso, a capacidade do FAT de expandir ou mesmo manter a prestação dos serviços previstos no SPETR foi fortemente afetada.

O primeiro grande impacto das desvinculações na dinâmica do FAT foi a ocorrência de déficit primário em 1995, algo inédito até então. Entre 1995 e 2004, o déficit resultante da diferença entre a receita líquida e o total de despesas referentes aos programas do SPETR sob sua alçada somou R \$ 54,4 bilhões. Porém, o montante desvinculado de suas receitas no mesmo período foi de R $\$ 95,4$ bilhões, ou seja, a soma de todo o déficit representou $57 \%$ da receita do FAT que foi apropriada pelo governo federal para atender outras despesas orçamentárias. Ainda assim, o déficit primário foi mais que compensado nesse período pelas receitas secundárias do fundo, provenientes de suas aplicações financeiras via bancos públicos, o que permitiu que seu patrimônio permanecesse em crescimento, saltando de R \$ 122,2 bilhões em 1995 para R \$ 219,3 bilhões em 2004 (uma média em torno de $8 \%$ ao ano). 
Quadro 1: Estrutura Orçamentária Simplificada do FAT

\begin{tabular}{|c|c|}
\hline ARRECADAÇÃO - PRINCIPAIS FONTES & OBRIGAÇÕES - PRINCIPAIS USOS \\
\hline $\begin{array}{l}\text { 1. Receita primária } \\
\text { 1.1. Arrecadação PIS-Pasep } \\
\text { 1.2. Cota-parte da contribuição sindical } \\
\text { 2. Receitas financeiras } \\
\text { 2.1. Remuneração (juros + correção monetária): } \\
\text { paga pelo BNDES sobre os repasses consti- } \\
\text { tucionais } \\
\text { 2.2. Remuneração (juros + correção monetária): } \\
\text { paga pelos agentes executores sobre os de- } \\
\text { pósitos especiais } \\
\text { 2.3. Remuneração (juros + correção monetária): } \\
\text { fundo extramercado (RML) } \\
\text { 2.4. Remuneração (juros + correção monetária): } \\
\text { recursos não desembolsados } \\
\text { 3. Outras receitas } \\
\text { 3.1. Restituição de benefícios não desembolsa- } \\
\text { dos } \\
\text { 3.2. Restituição de convênios } \\
\text { 3.3. Multas e juros devidos ao FAT } \\
\text { 3.4. Outras receitas patrimoniais }\end{array}$ & $\begin{array}{l}\text { 1. Desvinculações de recursos PIS-Pasep } \\
\left.\text { 1.1. FSE (EC } n^{\circ} 01 / 1994\right) \\
\left.\text { 1.2. FEF (EC } n^{\circ} 10 / 96\right) \\
\text { 1.3. DRU ( } E C n^{\circ} 27 / 2000 \text { à } E C n^{\circ} \text { 93/2016) } \\
\text { 2. Repasse BNDES ( } 40 \% \text { PIS-Pasep) } \\
\text { 3. Despesas constitucionais correntes } \\
\text { 3.1. Seguro-desemprego } \\
\text { 3.2. Abono salarial } \\
\text { 4. Outras despesas correntes } \\
\text { 4.1. Intermediação de emprego (Sine) } \\
\text { 4.2. Qualificação profissional } \\
\text { 4.3. Outras despesas } \\
\text { 5. Reserva Mínima de Liquidez (RML) } \\
\text { 6. Depósitos Especiais }\end{array}$ \\
\hline Total de Entradas $(1+2+3)$ & Total de Saídas $(1+2+3+4)$ \\
\hline
\end{tabular}

Fonte: Adaptado de Cardoso Jr. e Gonzalez (2007).

Obs.: Não estão inclusas as perdas com desonerações tributárias.

\section{A DINÂMICA FINANCEIRA RECENTE DO FAT (2005-2018)}

O período que abrange os anos de 2005 a 2018 não apenas reforça algumas tendências já observadas anteriormente como apresenta novos elementos de problematização dos fatores determinantes das políticas de mercado de trabalho no Brasil. Vale ressaltar que esse recorte temporal foi marcado por pelo menos dois momentos bastante antagônicos em termos de indicadores de mercado de trabalho: um em que se observou crescente queda do desemprego e elevação do estoque de empregos formais na economia brasileira, entre 2005 e 2014, e outro a partir de 2015 que, impactado por uma súbita crise econômica, houve uma elevação drástica do desemprego seguido de um retorno crônico da informalidade no mercado de trabalho (Oliveira e Silva, 2018). Tais fatores influenciaram diretamente na dinâmica financeira do FAT e, consequentemente, na operacionalização dos programas relacionados ao SPETR.

Para as análises aqui propostas, optou-se por uma sequência que engloba o fluxo de entrada de recursos, o fluxo de saídas, e, por fim, a variação patrimonial do FAT ao longo desse período especificado, contrastando com as decisões de política fiscal e mudanças no ambiente econômico que impactaram em sua trajetória. Para subsidiar o debate, a Tabela 1 apresenta um amplo conjunto de informações com a discriminação de todos os itens de receita, despesas e demais componentes do resultado nominal anual do FAT. 


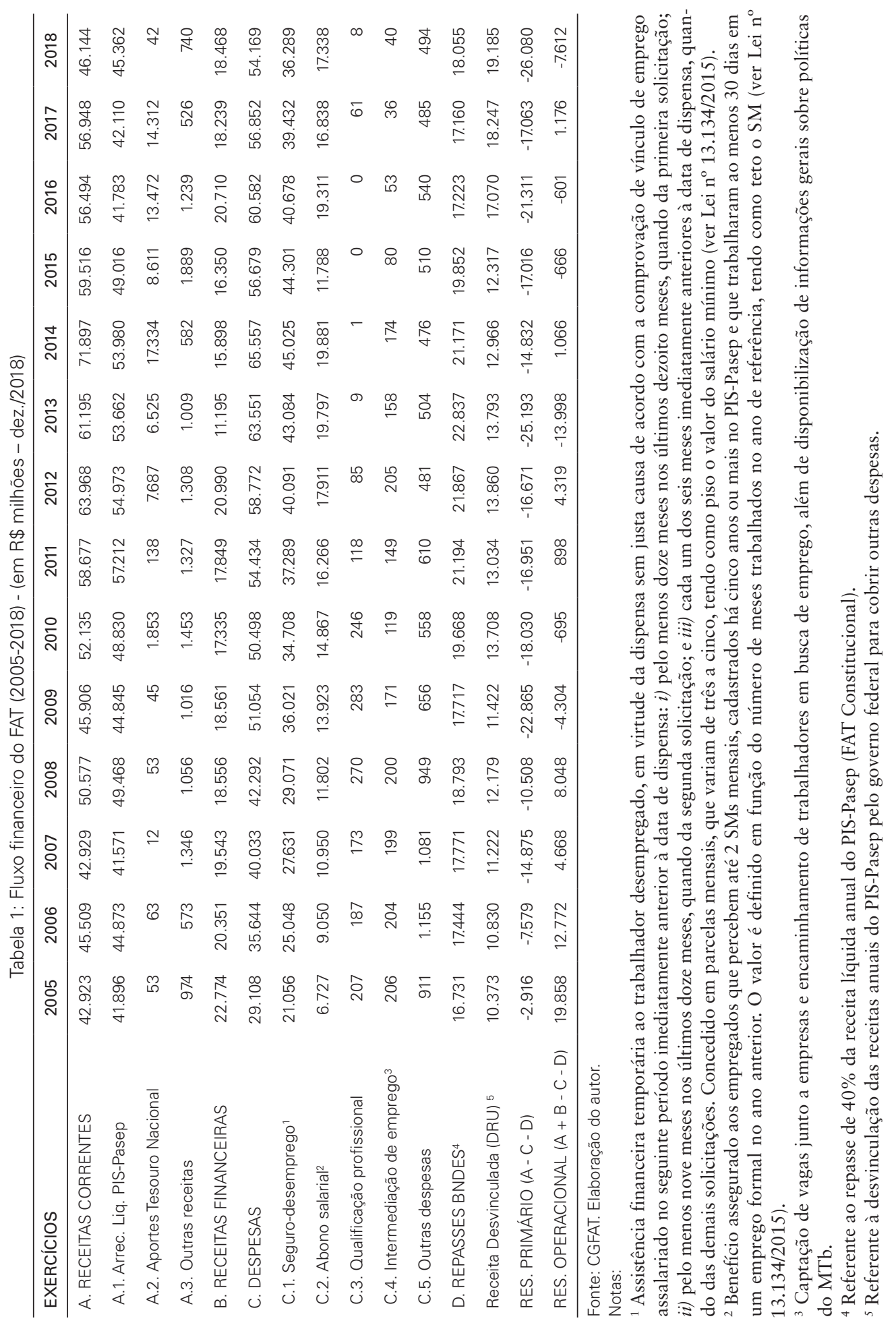




\section{O fluxo das entradas de recursos}

O fluxo anual de receitas (primárias e secundárias) do FAT apresentou uma variação real positiva ao longo do período, acompanhando a própria dinâmica da economia brasileira. Houve um crescimento frequente até 2014, com exceção de 2009 em decorrência dos impactos diretos da crise econômica global no ano anterior. Em 2015, já sob o início da crise política e econômica no Brasil, a trajetória de arrecadação do PIS-Pasep se reverteu. Essa queda aprofundou-se ainda mais após a aprovação no Congresso e sanção presidencial da Emenda Constitucional (EC) $n^{\circ} 476 / 2016$, que ampliou de $20 \%$ para $30 \%$ o percentual da DRU sobre as contribuições sociais, incluindo o PIS-Pasep, com vigência retroativa a partir de $1^{\circ}$ de janeiro de 2016. Em 2018 ocorreu uma ligeira recuperação das receitas do PIS-Pasep, mas seu valor atualizado ficou apenas próximo ao obtido em 2009.

Os recursos advindos das contribuições para o PIS-Pasep compuseram 65,1\% de toda a receita líquida. Já as receitas financeiras, que apresentaram variação positiva no período apesar de certa instabilidade, foram responsáveis por 30,3\% do total. No entanto, a participação crescente dessa fonte de receitas implica uma situação paradoxal para o fundo e para o próprio funcionamento do SPETR. Por um lado, a taxa de juros mais alta implica maiores remunerações sobre os ativos aplicados no mercado financeiro. Por outro, ela eleva o custo do investimento no país, o que compromete a busca por um nível mais significativo de crescimento econômico com aumento do nível de emprego e, consequentemente, elevação da própria arrecadação primária do FAT.

Destaca-se ainda a necessidade de aporte de recursos do Tesouro Nacional para o atendimento das despesas primárias do fundo a partir de 2010. No entanto, ao comparar com o total de receita desvinculada pelo governo federal ao longo de toda a série, nota-se que a soma desses aportes foi bem inferior, representando apenas $25,4 \%$ desse total. Somente em 2014 o aporte do Tesouro foi superior ao montante desvinculado. Ainda assim, o fluxo de recursos orçamentários da União contribuiu para aumentar a pressão política sobre os gastos com os programas do SPETR.

Outra decisão de política fiscal que influiu negativamente no crescimento dos recursos via PIS-Pasep refere-se às medidas de desoneração tributária tomadas pelo governo federal, com a intenção declarada de incentivar o setor produtivo para minimizar os impactos negativos da crise econômica global iniciada em 2008. De acordo com estimativas dos Demonstrativos de Gastos Tributários apresentadas nos Projetos de Lei Orçamentária Anual, as desonerações sobre a contribuição do PIS-Pasep foram em torno de R \$ 13,2 bilhões em 2018, valor que, por sua vez, representou $29,1 \%$ de toda a receita primária líquida do fundo no mesmo ano (R\$ 45,3 bilhões). Em 2014 e 2015 as perdas estimadas com as desonerações chegaram a ser maiores que o montante desvinculado via DRU. A partir de 2016, com o aumento do percentual da DRU para $30 \%$ (EC n ${ }^{\circ} 476 / 2016$ ), o total desvinculado cresce significativamente e supera as desonerações estimadas.

Para uma melhor verificação sobre a evolução recente desses indicadores, o 
Gráfico 1 permite não apenas acompanhar a trajetória desses "vazamentos" de receita em função das decisões de política econômica do governo federal, mas também verificar sua relação com o déficit primário (receitas correntes menos despesas) do FAT. Por ele nota-se que, durante toda a série analisada, apenas em 2009, ano de forte retração da receita, o valor do déficit primário foi levemente superior. No acumulado do período, foram $\mathrm{R} \$ 341$, 4 bilhões de perdas de receitas via esses instrumentos contra $\mathrm{R} \$ 231,9$ bilhões de déficit primário, o que representa uma diferença de R $\$ 109,5$ bilhões.

Gráfico 1: Evolução das desonerações e desvinculação da contribuição

do PIS-Pasep em relação ao déficit primário do FAT (em bilhões - valores de dez./2018)

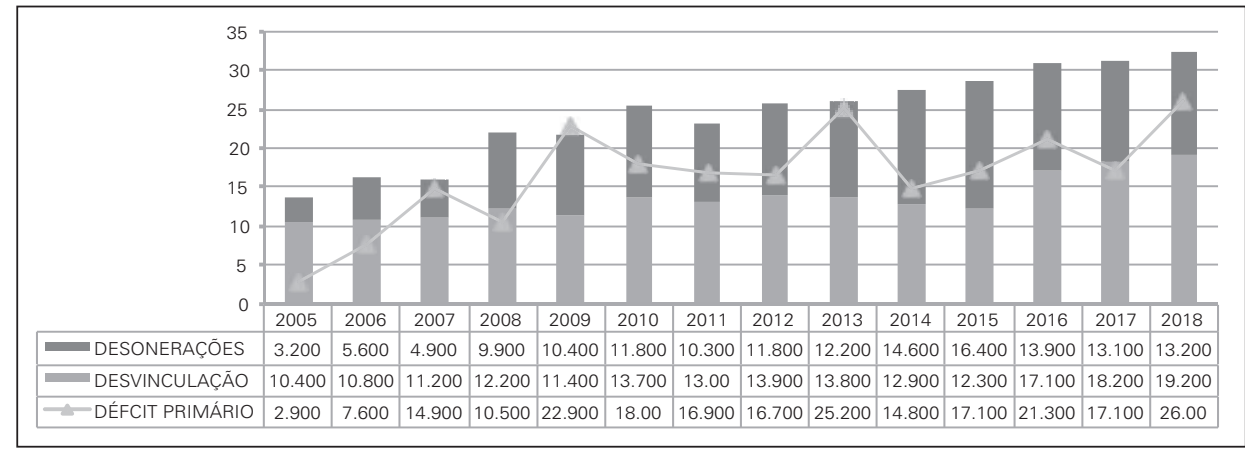

Fonte: CGFAT. Elaboração do autor.

No caso das remunerações financeiras, há de se observar mudanças importantes nas trajetórias da Taxa de Juros de Longo Prazo (TJLP) e da Selic ao longo da série, pois são determinantes na remuneração das disponibilidades financeiras do FAT aplicadas na rede bancária. No caso da TJLP, houve uma queda contínua no indicador, partindo de uma taxa média de $8 \%$ ao ano no início para $5 \%$ ao ano final do período analisado. ${ }^{5}$ Quanto à Selic, o comportamento foi bem mais volátil, com um movimento instável de altas e baixas. Com a crise econômica experimentada a partir de 2015, a taxa básica de juros voltou a decair no final de 2016. Essas duas trajetórias ajudam a entender o comportamento das receitas de aplicações financeiras, expressas anteriormente na Tabela 1, que caíram em 2013, se recuperaram somente em 2016, e apresentaram nova queda em 2017. Outro fator explicativo é a queda das próprias aplicações do FAT em Depósitos Especiais, o que vem ocorrendo desde 2007, dadas as limitações geradas pelo aumento dos gastos com o seguro-desemprego e com o abono salarial, a ser debatido com mais detalhes na próxima seção.

Por fim, o item "outras receitas" apresentou uma trajetória bastante instável ao longo do período, chegando ao seu maior valor em 2015, com R \$ 1,9 bilhão.

\footnotetext{
${ }^{5}$ A Lei n ${ }^{\circ}$ 13.483/2017, decorrente da MP n ${ }^{\circ} 777$, criou uma nova Taxa de Longo Prazo (TLP).
} 
Seu principal componente refere-se à cota-parte da contribuição sindical. Porém, a Reforma Trabalhista sancionada pelo então presidente Michel Temer em 2017 (Lei $\mathrm{n}^{\circ}$ 13.467) extinguiu a contribuição sindical obrigatória, o que certamente trará impactos negativos para a arrecadação dessa fonte. Como esse item possui um valor residual em relação ao montante de entradas do fundo (responsável por menos de $2 \%$ do total de receitas), sua variação não refletiu em grande impacto para o resultado econômico geral.

Portanto, esta seção mostrou que decisões de política econômica nos últimos anos afetaram consideravelmente a capacidade de financiamento do FAT, causando vazamentos significativos em sua fonte primária de receita. Destacam-se, nesse sentido: i) a elevação das desonerações tributárias do PIS-Pasep, estratégia reforçada para alavancar a atividade produtiva nacional após a crise do capitalismo global em 2008, mas que se manteve nos anos seguintes; e ii) a sanção da $\mathrm{EC} \mathrm{n}^{\circ}$ 476/2016, que resultou na elevação da DRU de $20 \%$ para $30 \%$ sobre contribuições sociais. Tais fatores, aliados ao movimento de elevação dos gastos com os programas de garantia de renda (seguro-desemprego e abono salarial), vem enfraquecendo bastante as disponibilidades de caixa do FAT para suprir suas demandas programáticas, como pode ser conferido na seção seguinte.

\section{O fluxo das obrigações}

Pelo lado das destinações de recursos, a Lei n ${ }^{\circ}$ 7.998/1990 expressa que o FAT deve financiar o seguro-desemprego, que abrange a assistência financeira ao trabalhador desempregado, e o abono salarial, que fornece um complemento de renda a trabalhadores formais com baixa remuneração, além de outras ações que auxiliem na busca e na preservação do emprego, as quais se destacam os programas de intermediação de emprego e de qualificação profissional. Os gastos são gerenciados pelo MTb e fazem parte das despesas correntes do FAT. Outras obrigações, como já frisado anteriormente, referem-se à formação da RML, aos repasses ao BNDES e aos Depósitos Especiais.

Os números referentes ao período de análise mostram que a despesa apresentou elevação superior ao crescimento do PIB - 51,8\% contra 27,9\%. Apenas em cinco anos desse intervalo temporal ocorreram relações anticíclicas entre os dois indicadores: em 2006 e 2017, com o aumento do PIB e a queda nas despesas, e em 2009, 2015 e 2016, com queda do PIB e elevação das despesas referentes ao FAT.

Ao observar o comportamento dos componentes da despesa, nota-se que o custeio dos benefícios do seguro-desemprego e do abono salarial cresceu bem acima tanto das receitas primárias líquidas quanto do total das obrigações do fluxo anual do FAT. Para se ter uma ideia, a soma desses dois itens de despesa foi $18,5 \%$ superior ao total da receita primária líquida do fundo em 2018 , já descontada a DRU, enquanto em 2005 os gastos com benefícios dos dois programas respondiam por cerca de $2 / 3$ da receita primária líquida. Por serem gastos obriga- 
tórios previstos na CF/1988, ambos não estão sujeitos a contingenciamentos orçamentários.

Porém, o crescimento da participação desses dois itens no total das despesas do FAT faz com que o espaço financeiro para os demais programas do SPETR se torne mais exíguo. As ações de qualificação profissional e intermediação de emprego, que juntas chegaram a representar $9 \%$ de toda a despesa corrente do FAT em 2000, passaram a ter sua participação cada vez mais reduzida ao longo dos anos, estabilizando-se abaixo de $1 \%$ no período mais recente (item “outras despesas" do Gráfico 2). Por serem despesa de natureza discricionária, esses serviços são frequentemente alvo de contingenciamento para fins de ajuste fiscal. Dessa forma, não apenas os programas de ativação do mercado de trabalho ficaram praticamente sem recursos para sua execução, quanto o próprio sistema como um todo passou a ser pressionado por mudanças de adequação fiscal ao novo arcabouço normativo que rege a dinâmica financeira do fundo.

Gráfico 2: Evolução da composição das obrigações totais do FAT - 2005-2018 (em \%)

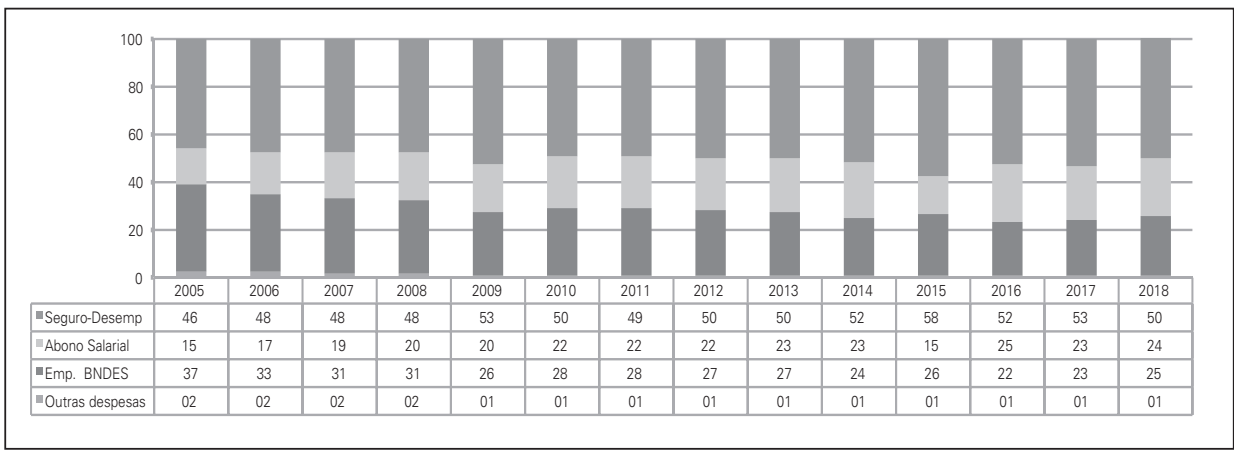

Fonte: CGFAT. Elaboração do autor.

Nesse sentido, torna-se relevante um aprofundamento sobre os determinantes principais para a aceleração dos gastos com seguro-desemprego e abono salarial no país na última década, dado que esse resultado impacta diretamente na operacionalidade do conjunto dos programas. Para se chegar a possíveis entendimentos sobre essa questão é preciso destacar alguns pontos relevantes.

No caso do seguro-desemprego, a despesa varia em função de três fatores: i) o valor do benefício; ii) o número de beneficiários; e iii) sua duração. Estudos apontam que a duração dos benefícios, isto é, o número de parcelas que cada beneficiário recebe do seguro-desemprego (item iii), pouco se modificou ao longo dos anos, mantendo-se em torno de 4,2 parcelas emitidas em média por beneficiário (Pires e Lima Jr., 2014; IPEA, 2015). Já o valor do benefício e o número de segurados cresceram significativamente desde 2005, e a combinação entre esses dois movimentos respondem pelo crescimento dos gastos. No primeiro, destaca-se o aumento real do salário mínimo ao longo desse período $(55,7 \%)$, sobretudo em 
função da política de valorização assumida pelo governo federal a partir de $2009 .{ }^{6}$ A CF/1988 estabeleceu o salário mínimo corrente como piso para os benefícios sociais, o seguro-desemprego, o que eleva o valor médio de cada parcela em virtude de sua valorização real.

Como forma de amenizar essa relação, o método de cálculo de reajuste do valor das parcelas que excedem a 1 SM foi alterado em 2013 pelo Codefat, passando a ser definido pelo INPC, e não mais pelo percentual aplicado ao valor salarial, apesar da posição contrária das representações sindicais do conselho (Silva, 2019a). Com isso, os ganhos reais sobre o valor do salário mínimo deixaram de ser incorporados às parcelas que excedessem o piso constitucional. A parcela mínima permaneceu indexada ao valor corrente do salário mínimo.

Já no tocante ao número de segurados, o fator determinante é o estoque de trabalhadores formais. No período entre 2005 e 2014 esse número cresceu 49,1\%, chegando a 49,6 milhões de trabalhadores formalizados, pico histórico no país. Nos anos 2015 e 2016 houve uma queda acentuada nesse contingente, com a eliminação de 3,5 milhões de postos de trabalho registrados na economia brasileira, acompanhada por uma relativa estabilidade nos dois anos seguintes, encerrando o período com 46,3 milhões de postos formais de trabalho (Oliveira e Silva, 2018). Ainda assim, ao se comparar a variação em todo o período - 2005 a 2018 -, houve um crescimento na ordem de $39,2 \%$. Por esses motivos, a elevação acumulada nos gastos com o seguro-desemprego se deve também à significativa ampliação do estoque de emprego formal no período, pois com isso aumenta-se a base de trabalhadores sujeitos a cumprir as condições de acesso ao benefício, aumentando a cobertura de atendimento do programa.

Um dos elementos que potencializam essa relação entre aumento do estoque de trabalhadores formalizados e aumento dos gastos com seguro-desemprego é o grau de rotatividade da força de trabalho, considerada uma característica marcante do mercado de trabalho brasileiro (DIEESE, 2014; Gonzaga e Pinto, 2014). Ou seja, a complementaridade entre aumento da formalização do emprego e manutenção de altas taxas de rotatividade ajuda a desvendar o aparente paradoxo sobre a elevação de gastos com seguro-desemprego mesmo durante um momento de queda contínua do desemprego no país, como ocorreu entre 2005 e 2014. Na prática, o total de beneficiários do seguro-desemprego subiu em um patamar muito próximo à elevação do estoque de trabalhadores formais no Brasil, dada a manutenção de altas taxas de rotatividade no mercado de trabalho. Para uma melhor comparação visual, o Gráfico 3 apresenta as trajetórias referentes ao gasto anual, ao número de beneficiários e ao percentual de segurados em relação ao estoque de trabalhadores formais no Brasil.

\footnotetext{
${ }^{6}$ Pela regra (Lei no $12.255 / 2009$ ), o valor do SM passa a ser calculado com base na variação do PIB com dois anos de defasagem mais a inflação do ano anterior, medida pela variação acumulada do INPC no período de referência (IPEA, 2015).
} 
Gráfico 3: Gasto, número de beneficiários e percentual de beneficiários do seguro-desemprego sobre o estoque de trabalhadores formais - 2005-2018 (valores dez./2018)

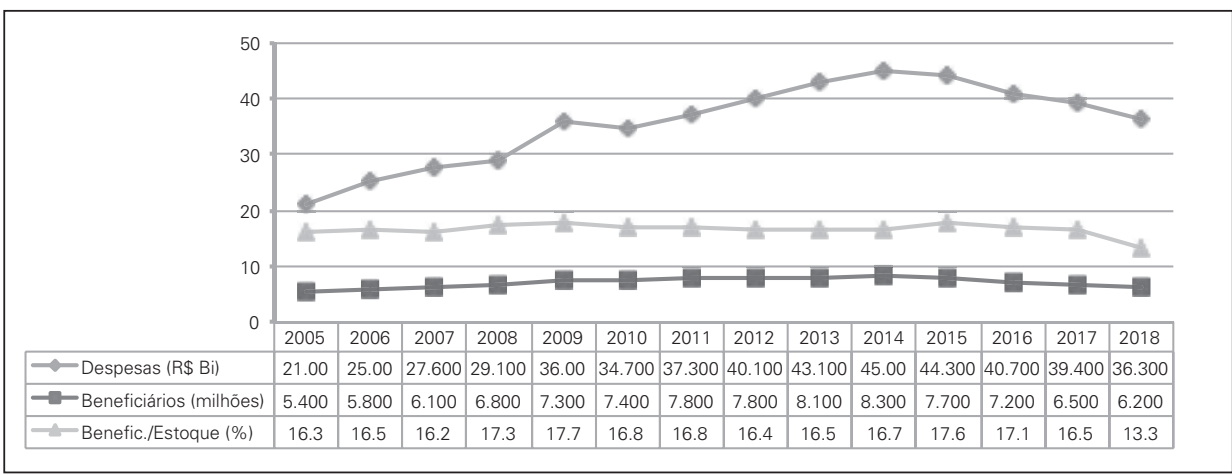

Fonte: CGFAT. Elaboração do autor.

Pode-se notar pelos números mostrados que a taxa de crescimento anual do valor monetário despendido no período ao longo do período foi bem superior à taxa referente ao número de trabalhadores atendidos, sobretudo em função da política de valorização do salário mínimo. Porém, tanto o volume global de despesas com o programa quanto o número de beneficiários vêm diminuindo desde 2015, o que provavelmente deriva de dois fatores: a queda do estoque de trabalhadores formais e a entrada em vigor da Lei $\mathrm{n}^{\circ} 13.134 / 2015$, que endureceu as regras de acesso ao benefício.

Apesar da trajetória de crescimento nos gastos com seguro-desemprego, há de se ressaltar que o Brasil não possui uma despesa alta em proporção ao PIB com esse programa para os padrões internacionais. Se comparado com os países da Organização para a Cooperação e Desenvolvimento Econômico (OCDE), por exemplo, o Brasil ocupa uma posição intermediária, com uma despesa em torno de 0,6\% do PIB, abaixo de Estados Unidos, Bélgica, França e Espanha, que apresentam índices próximos ou superiores a $1 \%$ do PIB. Em contraste, como constataram Pires e Lima Jr. (2014), o número de beneficiários é relativamente elevado no Brasil, com uma média de 7,6\% do total de trabalhadores, ficando atrás apenas de Espanha (10,3\%), Bélgica $(8,8 \%)$ e França $(8,6 \%)$, enquanto países como Polônia $(1,8 \%)$ e Chile $(1,7 \%)$ possuem as menores taxas de cobertura do programa.

Com relação ao abono salarial, o reajuste do salário mínimo atuou tanto na elevação do valor do benefício quanto no dimensionamento do público que tem direito a recebê-lo, pois, à medida que seus aumentos têm comprimido a dispersão dos salários na economia, o público coberto pelo abono tende a crescer (IPEA, 2011; Corseuil, Foguel e Tomelin, 2015; Silva, Amorim e Russo, 2020). Isso implica, juntamente com a evolução no número de trabalhadores formalizados, o principal fator responsável pelo crescimento do número de beneficiários do abono salarial, que saltou de 9,7 milhões para 24 milhões de trabalhadores no período avaliado. 
Em termos da trajetória anual de gasto do abono salarial, o Gráfico 4 apresenta os valores dispendidos, o número de beneficiários e seu percentual em relação ao estoque de trabalhadores formais. As curvas de evolução do gasto, assim como ocorreu no seguro-desemprego, mostram uma variação superior ao crescimento do número de beneficiários, também sob influência do aumento real do salário mínimo. Mas, diferentemente do seguro-desemprego, o percentual de beneficiários do abono apresentou uma elevação contínua ao longo do período, saltando de $29,2 \%$ em 2005 para 49,8\% em 2017. Isso se deu em função da já comentada elevação da quantidade de trabalhadores admitidos na faixa até $2 \mathrm{SM}$ em relação ao estoque total da força de trabalho formalizada no país.

Gráfico 4: Gasto, número de beneficiários e percentual de beneficiários do abono sobre o estoque de trabalhadores formais - 2005-2018 (valores dez./2018)

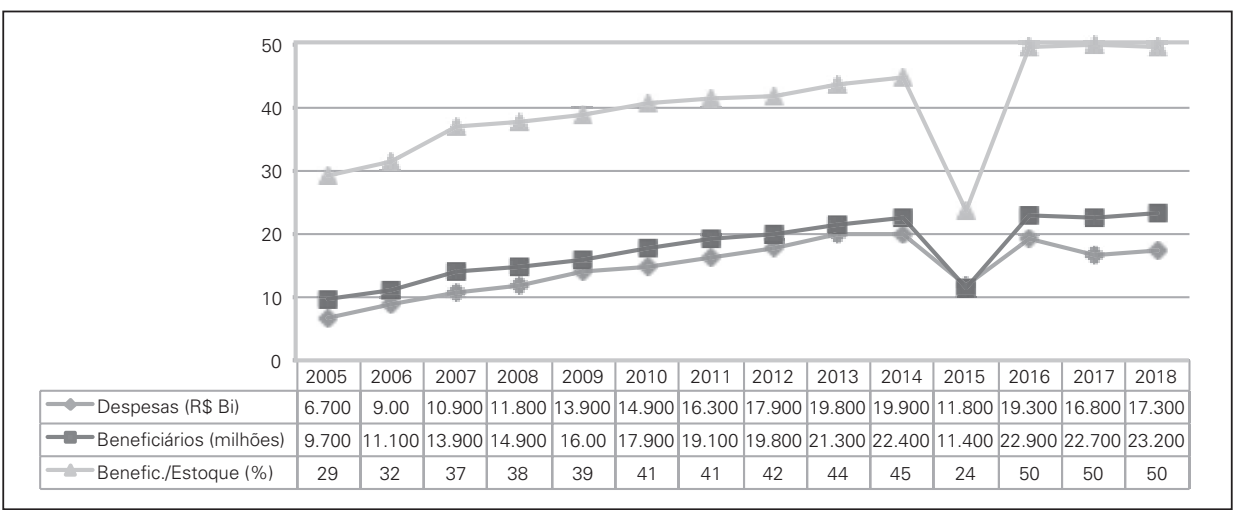

Fonte: CGFAT. Elaboração do autor.

Vale destacar ainda alguns pontos referentes aos gastos com o abono salarial, visando uma compreensão para além do que os números mostram. Primeiro, a forte variação da quantidade de beneficiários no final da série (queda acentuada em 2015, seguida de aumento em 2016) ocorreu devido a uma alteração do cronograma de pagamento do período de julho de 2015 a junho 2016. ${ }^{7}$ Com isso, uma parte dos trabalhadores que tinha o direito em 2015 só pôde receber o abono no ano seguinte, esvaziando assim a concessão de benefícios em 2015 e inflando em 2016. O segundo fator é que entraram em vigor em 2015 as novas regras de pagamento (Lei $\left.\mathrm{n}^{\circ} 13.134 / 2015\right)$, estabelecendo que o valor do benefício passasse a ser "calculado na proporção de 1/12 (um doze avos) do valor do salário mínimo vigente na data do respectivo pagamento, multiplicado pelo número de meses trabalhados no ano correspondente" (art. $\left.9^{\circ}\right)$. Pela regra anterior, bastava haver trabalhado um mês no ano de referência para que o trabalhador tivesse o direito ao recebimen-

${ }^{7}$ Sobre o processo que levou a essa decisão no Codefat, ver Silva (2019a). 
to de 1 SM. ${ }^{8}$ Essa nova regra impediu que o gasto com abono salarial nesses três últimos anos da série fosse ainda maior. ${ }^{9}$

Por fim, no item "outras despesas" encontram-se embutidos os custos operacionais diversos do MTb no campo dos programas do SPETR, incluindo gastos com: i) manutenção dos programas (ações de apoio ao pagamento dos benefícios do seguro-desemprego e do abono salarial); ii) custeio de Pesquisas sobre Emprego e Desemprego (PED), elaboradas pelo Dieese; iii) manutenção de bancos de dados; iv) informatização e distribuição de Carteira de Trabalho e Previdência Social (CTPS); v) estudos de avaliação dos programas; vi) campanhas educativas e informativas; vii) apoio ao Codefat; viii) manutenção das unidades regionais do $\mathrm{MTb}$, entre outros (Brasil, 2015). Apesar da grande quantidade de ações, elas são pouco significativas com relação ao fluxo de saídas do FAT, representando $0,9 \%$ do total de despesas em 2018 (ver Tabela 1).

Em síntese, a evolução das despesas correntes do FAT no período avaliado está diretamente relacionada às transformações em curso na estrutura ocupacional e salarial brasileira. Nesse contexto, para que o fundo mantenha seu equilíbrio contábil, torna-se necessário que a economia volte a apresentar taxas de crescimento que garantam maior fluxo de arrecadação, mantidos os parâmetros atuais de seu financiamento. Porém, também deve-se garantir que qualquer "vazamento" de receitas do sistema via política fiscal seja compensado, para evitar desequilíbrios como esses analisados ao longo da seção. Do contrário, a pressão sobre mudanças mais abruptas no arranjo institucional do FAT, com sua consequente descapitalização, pode resultar em deturpações ainda maiores na estrutura do SPETR. A Lei $\mathrm{n}^{\mathrm{o}} 13.134 / 2015$ foi um exemplo, ao enrijecer as regras de acesso ao seguro-desemprego e alterar a fórmula de cálculo para o benefício do abono salarial, sem que houvesse nenhuma reversão da economia com esses dois programas para outras ações previstas no sistema.

Na próxima seção são abordados os impactos dos movimentos de entradas e despesas discutidos até aqui sobre a evolução patrimonial do FAT.

\section{Resultado nominal e evolução patrimonial}

Para analisar o comportamento recente do patrimônio do FAT torna-se necessário verificar a evolução do seu "Resultado Nominal", determinado pela diferença entre os totais de receitas e despesas em seus balanços anuais. Ele indica se o FAT tem sido capaz de cumprir suas obrigações constitucionais de financiar o seguro-desemprego e o abono salarial, bem como manter as transferências obrigató-

\footnotetext{
${ }^{8}$ A exigência adicional de um prazo mínimo de cinco anos de inscrição no PIS-Pasep para receber o benefício foi mantida.

${ }^{9}$ Para uma análise mais pormenorizada sobre o abono salarial no Brasil, ver Silva, Amorim e Russo (2020).
} 
rias ao BNDES, além de outras despesas correntes que lhes forem atribuídas, como os demais programas que compõem o SPETR.

O gráfico a seguir apresenta essas trajetórias para o período em análise. Por ele nota-se que em seis anos o resultado nominal auferido foi negativo: 2009, 2010, 2013, 2015, 2016 e 2018. Nos anos de 2012 e 2014 o resultado positivo só foi possível devido ao aumento do repasse do Tesouro Nacional.

Gráfico 5: Receitas e obrigações totais do FAT - 2005-2018

(em bilhões - valores de dez./2018)

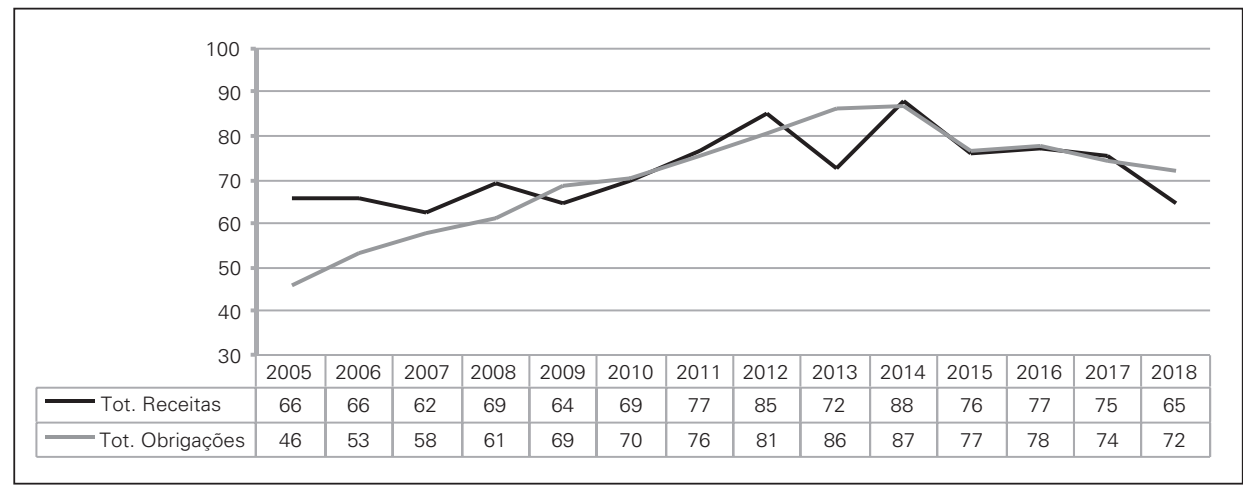

Fonte: CGFAT. Elaboração do autor.

O crescimento das receitas tem se dado continuamente a uma taxa média inferior ao das obrigações, ${ }^{10}$ sobretudo em função do aumento já discutido das perdas de receitas com desvinculações orçamentárias e isenções tributárias, além dos impactos das crises de 2008 e 2015-16. Pelo lado das despesas, o impacto maior é marcado pelos gastos com o seguro-desemprego e o abono salarial, em virtude de alterações nos indicadores de mercado de trabalho, conforme observado na seção anterior. O pior resultado nominal foi apurado em 2013, quando essa diferença chegou a R \$13,2 bilhões, explicado em parte por uma queda acentuada da receita de remunerações financeiras. Em 2018 o resultado voltou a apresentar forte déficit, após quatro anos de relativa estabilidade contábil.

Vale ressaltar que a arrecadação do PIS-Pasep, isoladamente, já não cobre o conjunto de obrigações do FAT desde 1995, quando passou a vigorar a desvinculação de $20 \%$ de suas receitas primárias para fins de ajuste fiscal do governo federal. Esse desequilíbrio foi coberto até com certa folga pelas demais receitas do fundo, sobretudo as receitas financeiras. Porém, isso deixou de ocorrer sistematicamente a partir de 2009, quando houve seu primeiro déficit operacional (ver Tabela 1).

Tal conjuntura demonstra a dificuldade do FAT em saldar suas obrigações sob o arranjo institucional a que ele passou a ser submetido ao longo dos anos, agra-

\footnotetext{
${ }^{10} \mathrm{Em} 2017$ ocorreu queda nas receitas e nas obrigações. Porém, a queda nas receitas foi inferior à queda das obrigações $(0,9 \%$ contra $3,2 \%)$.
} 
vado com a elevação das desonerações tributárias em 2009 e do percentual da DRU em 2016. E essa não é uma questão que se resolva apenas com a medida clássica de corte de despesas, porque o crescimento dos gastos com o seguro-desemprego e com o abono salarial, como mostrado anteriormente, está associado a dinâmicas positivas para o mercado de trabalho brasileiro, tais como a formalização do emprego e o crescimento real do valor do salário mínimo.

Apesar desses desequilíbrios observados, os dados contábeis apontam que o arranjo institucional do FAT lhe permitiu uma significativa trajetória de crescimento patrimonial, variando 30,3\% em termos reais entre 2005 e 2018 (Tabela 2). Essa evolução patrimonial, mesmo com a elevação das despesas correntes e os vazamentos na sua base primária de receitas, deve-se especialmente ao rendimento de aplicações financeiras (assim como ocorreu no período 1995-2004). As taxas Selic e TJLP, referências básicas para a remuneração das aplicações do FAT, foram bem superiores às médias da taxa de inflação e da variação real do PIB durante o período em análise.

Porém, dois fatores valem ser considerados sobre o contexto atual. Primeiro, há um movimento de queda na taxa de juros Selic em virtude da forte recessão da economia brasileira a partir de 2015, o que afeta a remuneração futura dos ativos financeiros do fundo, ainda que isso possa ser compensado caso a queda dos juros seja acompanhada por elevação dos investimentos e crescimento econômico. Segundo, em virtude do aumento de gastos com os principais programas, as disponibilidades monetárias para Depósitos Especiais foram se tornando menores durante a série, restringindo a possiblidade de expansão das linhas específicas de crédito a micro e pequenas empresas. ${ }^{11}$ Ademais, a ocorrência de déficits nominais obriga ao Codefat a se desfazer de parte de seu patrimônio financeiro, formado pelo montante repassado ao BNDES e demais aplicações, o que tende a comprometer as próprias receitas futuras advindas dessas aplicações.

Todo esse movimento quantitativo pode ser evidenciado a partir da análise da participação relativa de cada um dos componentes do patrimônio nesses últimos anos, conforme ilustrado no Gráfico 6. A modalidade Depósitos Especiais, que chegou a representar $37,5 \%$ do total, iniciou uma queda sistemática a partir de 2008 , terminando a série com apenas 5,7\% de participação em 2018. Já o componente do FAT Constitucional, referente aos repasses anuais ao BNDES, cresceu de $56,5 \%$ para $81,5 \%$ no mesmo período, revertendo uma relação de queda relativa de sua participação no decênio anterior (1995 a 2004). Por fim, a parcela do fundo extramercado (RML) permaneceu relativamente estável. Para complementar, a Tabela 2 apresenta a evolução dos valores anuais de cada item do patrimônio financeiro do FAT para o período 2005-2018.

\footnotetext{
${ }^{11}$ No caso específico dos Depósitos Especiais, houve uma queda brusca na concessão de crédito entre 2006, quando a concessão de crédito alcançou seu maior patamar ( $\$$ \$ 46,8 bilhões), e 2017, quando se registrou o menor valor da série (R \$ 4,7 bilhões). Para maiores informações, ver Silva (2019b).
} 


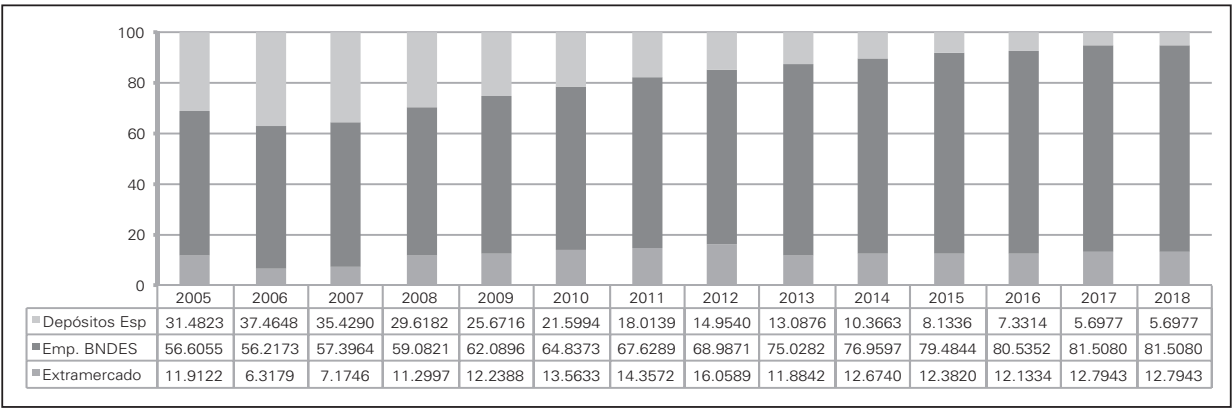

Fonte: CGFAT. Elaboração do autor.

Tabela 2: Patrimônio do FAT - saldos anuais - 2005-2018 (em R\$ bilhões - valores de dez./2018)

\begin{tabular}{cccccc}
\hline & $\begin{array}{c}\text { Fundo } \\
\text { Extramercado (a) }\end{array}$ & $\begin{array}{c}\text { Empréstimos } \\
\text { ao BNDES (b) }\end{array}$ & $\begin{array}{c}\text { Depósitos } \\
\text { Especiais (c) }\end{array}$ & $\begin{array}{c}\text { T OT A L } \\
(\mathrm{a}+\mathrm{b}+\mathrm{c})\end{array}$ & $\begin{array}{c}\text { Variação } \\
\text { Patrimonial } \\
\text { (Ano - \%) }\end{array}$ \\
\hline 2005 & 28,1 & 133,8 & 74,4 & 236,3 & \\
2006 & 16,6 & 147,9 & 98,6 & 263,1 & 11,3 \\
2007 & 20,5 & 164,3 & 101,4 & 286,2 & 8,8 \\
2008 & 31,0 & 162,6 & 81,3 & 274,9 & $-4,0$ \\
2009 & 34,7 & 176,2 & 72,8 & 283,7 & 3,2 \\
2010 & 36,6 & 175,1 & 58,3 & 270,1 & $-4,8$ \\
2011 & 39,5 & 186,0 & 49,6 & 275,1 & 1,9 \\
2012 & 46,2 & 198,3 & 43,1 & 287,5 & 4,5 \\
2013 & 33,5 & 211,2 & 36,9 & 281,7 & $-2,0$ \\
2014 & 36,6 & 222,5 & 29,9 & 289,0 & 2,6 \\
2015 & 36,1 & 231,8 & 23,8 & 291,6 & 0,9 \\
2016 & 35,1 & 232,7 & 21,2 & 288,9 & $-1,0$ \\
2017 & 38,9 & 247,9 & 17,3 & 304,1 & 5,3 \\
2018 & 31,9 & 262,3 & 14,1 & 308,3 & 1,4 \\
\hline Variação (\%) & 36,2 & 95,9 & $-81,1$ & 30,3 & \\
$2005 / 2018$ & & & & & \\
\hline
\end{tabular}

Fonte: CGFAT. Elaboração do autor.

Portanto, o arranjo de financiamento projetado para o modelo de SPETR no Brasil vem enfrentando profundas complicações em sua operacionalidade, tornando cada vez mais complexa a economia política em torno do tema. O FAT foi atingido em diversas frentes nesses últimos anos, em razão de decisões de política fiscal que, mesmo sem uma quebra drástica na engenharia institucional original, 
resultaram no enfraquecimento de seu potencial de fomentar maior dinamicidade no mercado de trabalho, além de comprometer sua função precípua de proteção social aos trabalhadores. Essas decisões, embora implicassem efeitos diretos sobre a dinâmica do fundo, foram definidas e aprovadas em outros fóruns de poder, sem exigir qualquer negociação ou consentimento junto ao Codefat, o que demonstra uma hierarquia de poder decisório a interferir diretamente na capacidade de coordenação das políticas sociais (Silva, 2019a).

Nesse sentido, qualquer análise sobre a trajetória operacional e contábil do FAT não pode negligenciar essas medidas que resultaram no acúmulo de pequenas alterações nas regras originais de funcionamento, mas que ao longo do tempo resultaram em impactos graves e permanentes na estrutura de financiamento do SPETR brasileiro.

Isso não implica dizer, porém, que o sistema não necessite de ajustes. O arranjo operacional do FAT contém questões a serem enfrentadas e aperfeiçoadas, desde que para isso se respeitem as diretrizes originais que lhe conferem o caráter de um fundo de proteção e promoção de políticas voltadas ao bem-estar do conjunto de trabalhadores brasileiros. Quaisquer propostas precisam estar em conformidade com essas diretrizes, além de perpassar pelos fóruns indicados para a gestão e o acompanhamento de suas atividades, em especial o Codefat.

\section{CONSIDERAÇÕES FINAIS}

Como visto ao longo deste estudo, a trajetória de institucionalização e operacionalização das políticas de mercado de trabalho no Brasil abre possibilidades interessantes para a compreensão dos desafios que envolvem a inserção de políticas sociais na agenda governamental. As análises foram direcionadas ao potencial de financiamento dos programas que compõem o SPETR via receitas geradas pelo arranjo institucional do FAT.

Ficou constatado que, com o aumento dos gastos correntes ante as receitas, sobretudo em função dos programas constitucionais obrigatórios (seguro-desemprego e abono salarial), tal arranjo começou a mostrar sinais de fragilidade, uma vez que se diminuiu o espaço para custear despesas correntes discricionárias, como no caso dos programas de qualificação profissional e intermediação de emprego. Com isso, a ideia originária de um sistema público de emprego integrado se enfraquece, uma vez que seu sucesso está relacionado ao potencial de complementaridade entre as ações que o compõem.

Nessas condições, uma análise preliminar e parcial apontaria que o modelo de financiamento do FAT tem se tornado insuficiente para atender ao conjunto de obrigações que lhes foram direcionadas desde a CF/1988. Ademais, a necessidade de repasses do Tesouro Nacional para custear as despesas não cobertas em seus últimos exercícios contábeis favorece pressões no sentido de restringir os gastos desses programas, o que pode comprometer o grau de proteção social desejado, impondo sérios limites ao acesso. 
Entretanto, o que se defende neste texto é que o processo de esgotamento da capacidade de financiamento via FAT das políticas de emprego no Brasil possui distintos determinantes. Embora não se negue a possibilidade de ajustes no próprio desenho institucional, ${ }^{12}$ o principal vetor de esgotamento é oriundo de decisões de política econômica no âmbito do governo federal que drenaram receitas importantes para o funcionamento do sistema desde meados dos anos 1990, sem estabelecer nenhum mecanismo estável de compensação, com destaque para as desvinculações orçamentárias e, mais recentemente, as desonerações tributárias. Essas decisões resultaram em distorções anuais crescentes da relação receitas sobre despesas.

Como discutido, o FAT movimenta um montante significativo de recursos e acumulou um vultoso patrimônio desde o início de sua operacionalidade, o que despertou interesses variados dentro da própria estrutura estatal para controlar esses recursos. Esses interesses transcenderam até mesmo a esfera de deliberação criada para essa finalidade, que é o Codefat. Por isso, uma análise que se atenha somente à trajetória contábil será sempre incompleta caso não se leve em conta esse conjunto de medidas de cunho fiscalista que interferem diretamente em seu resultado operacional.

Vale ressaltar ainda que a compreensão de toda essa economia política do FAT se torna fundamental na própria defesa desse domínio de política social, pois à medida que se aprofundam as distorções na contabilidade do fundo, novos elementos discursivos para grupos de interesse que visem mudar ainda mais o arranjo institucional atual ganham força no debate político, no sentido de desresponsabilizar o máximo possível a estrutura de Estado pelo atendimento dos programas que ele abrange.

\section{REFERÊNCIAS BIBLIOGRÁFICAS}

AZEREDO, B. (1998) Políticas públicas de emprego. São Paulo: Abet.

BARRADAS, A. M. S. (1986) Fábrica PIPMO: 1963-1982. Dissertação de Mestrado - Fundação Getúlio Vargas, Rio de Janeiro.

CARDOSO JÚNIOR, J. C.; GONZALEZ, R. (2007) "Dilemas e alternativas ao financiamento das políticas públicas de trabalho e renda no Brasil”. Brasília: Ipea.: Texto para Discussão, n. 1313.

CARVAlHO, J. M. (2002) Cidadania no Brasil. Rio de Janeiro: Civilização Brasileira.

CORSEUIL, C. H.; FOGUEL, M.; TOMELIN, L. F. (2015) "Evolução recente do tamanho do Programa de Abono Salarial". Caderno do Observatório Nacional do Mercado de Trabalho, v. 1.

DIEESE - DEPARTAMENTO INTERSINDICAL DE ESTATÍSTICA E ESTUDOS SOCIOECONÔMICOS (2014) Rotatividade e políticas públicas para o mercado de trabalho. São Paulo: DIEESE.

ESPING-ANDERSEN, G. (1990) The three worlds of welfare capitalism. Princeton: Princeton University Press.

GONZAGA, G.; PINTO, R. C. (2014) "Rotatividade do trabalho e incentivos da legislação trabalhista”. Rio de Janeiro: PUC, Texto para Discussão, n. 625.

\footnotetext{
${ }^{12}$ Propostas de ajustes no desenho institucional do FAT são debatidas em Silva (2018).
} 
IPEA - INSTITUTO DE PESQUISA ECONÔMICA APLICADA. (2011) Brasil em desenvolvimento 2011. Brasília: Ipea.

IPEA - INSTITUTO DE PESQUISA ECONÔMICA APLICADA (2015) Políticas sociais: acompanhamento e análise. Brasília: Ipea, n. 23.

KERSTENETZKY, C. L. (2012) O Estado do bem-estar social na idade da razão. Rio de Janeiro: Campus.

OLIVEIRA, T.; SILVA, S. P. (2018) “CF 30 anos: regulação e dinâmica do mercado de trabalho.” In: CARDOSO JÚNIOR, J. C. (Org.). A Constituição golpeada: 1988-2018. São Paulo: Perseu Abramo.

PIRES, M. C.; LIMA JÚNIOR, A. B. (2014) “Análise econômica do programa seguro-desemprego". Mercado de Trabalho: conjuntura e análise. Brasília: Ipea, n. 56.

POCHMANN, M. (2008) "Rumos da política do trabalho no Brasil”. In: SILVA, M. O.; YAZBERK, M. C. (Org.). Políticas públicas de trabalho e renda no Brasil. São Paulo: Cortez.

SILVA, S. P. (2018) "Propostas de reformulação no arranjo de financiamento e da agenda programática do sistema público de emprego, trabalho e renda no Brasil”. Mercado de Trabalho: conjuntura e análise. Brasília: Ipea, n. 65.

SILVA, S. P. (2019a). "A dimensão político-relacional das políticas de mercado de trabalho no Brasil: a agenda deliberativa do Codefat”. Brasília: Ipea, Texto para Discussão, n. 2503.

SILVA, S. P. (2019b) "Capacidades estatais para o financiamento do investimento no Brasil: uma análise da relação institucional de complementaridade entre FAT e BNDES”. Brasília: Ipea, Texto para Discussão, n. 2525.

SILVA, S. P. (2020a). “O paradigma do Sistema Público de Emprego da OIT e sua construção histórica no Brasil”. Brasília: Ipea, Texto para Discussão, n. 2562.

SILVA, S. P. (2020b). "A inclusão produtiva como eixo de política de proteção social: contexto latino-americano e questões para a realidade brasileira”. Brasília: Ipea, Texto para Discussão, n. 2605.

SILVA, S. P.; AMORIM, B.; RUSSO, F. M. (2020) "Perfil dos Beneficiários do Abono Salarial no Brasil e Proposta de Ação Emergencial no Contexto do Covid-19”. Brasília: Ipea, Nota Técnica da Disoc, n. 76. 